\title{
Step-wise Analysis of Dental Implant Insertion Process using Finite Element Technique
}

\author{
RUDI C. VAN STADEN ${ }^{1}$, HONG GUAN ${ }^{1}$, NEWELL W. JOHNSON ${ }^{2}$, YEW-CHAYE LOO ${ }^{1}$, NEIL \\ MEREDITH $^{3}$ \\ ${ }^{1}$ School of Engineering, Griffith University Gold Coast Campus, Australia; \\ ${ }^{2}$ School of Dentistry and Oral Health, Griffith University Gold Coast Campus, Australia; \\ ${ }^{3}$ Neoss Ltd, Harrogate, United Kingdom
}

July 2006

Address correspondence to Mr Rudi van Staden. School of Engineering, Griffith University Gold Coast Campus, PMB 50 Gold Coast Mail Centre, Queensland 9726, Australia. Telephone number: +61 (0)7 5552 8564. Fax number: +61 (0)7 5552 8065. Electronic mail: r.vanstaden@griffith.edu.au 
Keywords: Dental implant; Implantation procedure; Finite element technique

Subject Classification: Engineering application in dental implant research

VAN STADEN, R.C., GUAN, H., JOHNSON, N.W., LOO, Y.C., MEREDITH, N.,

\title{
Step-wise Analysis of Dental Implant Insertion Process using Finite Element Technique
}

\author{
Clinical Oral Implants Research
}

Objectives: Using the Finite Element Method (FEM), the insertion process of a dental implant into a section of the human mandible is analysed. The ultimate aim of this article is to advance the use of an innovative engineering approach in dental practices, especially in the process of dental implantation.

Material and Methods: The FEM and analysis techniques are used to replicate and evaluate the stress profile created within the mandible during the implantation process.

Results: The von Mises stress profiles in both cancellous and cortical bone are examined during implant insertion. The applied torque and the insertion stage are found to strongly influence the resulting stress profile within the surrounding jawbone.

Conclusions: Through the combination of both dental and engineering expertise, a simplified and efficient modelling technique is developed. This improves the understanding of the biomechanical reaction that the jawbone exhibits due to the insertion of implant. The current research is a pilot study using the FEM to model and simulate the dental implantation process. The assumptions made in the modelling and simulation process are: (1) the implantation process is simulated as a step-wise process instead of a continuous process; (2) the implant is parallel threaded and the implant does not rotate during insertion into the jawbone. Although the modelling and simulation techniques had to be simplified, a significant amount of information is gained which helps lay a good foundation for future research. Recommendations for future studies include the variation of the torque applied during the implantation process and upgrading the software capabilities to simulate the full dynamical process of implantation. 


\section{Introduction}

Dental implants are biocompatible screw-like titanium 'fixtures' that are surgically placed into a jawbone to replace missing teeth. The process of implantation requires an optimum stress profile in order to maintain a strong and healthy jawbone: a stress which is too high may cause irreversible damage to the jawbone; one that is too low may fail to stimulate the jawbone sufficiently for satisfactory healing of the wound and thus, for osseointegration. Implants are expected to function for a life-long period. Without the correct implantation technique an implant may fail shortly after insertion. The method by which the implant is placed into the jawbone plays a vital role for it to be biologically accepted by the surrounding jawbone. Clinical observations have indicated that there is a direct relationship between the insertion torque, the insertion speed and the success rate of implantation (Ottoni et al. 2005). The focus of this paper is on the stress profile produced within both the cortical and cancellous bone under an assumed method of implant insertion.

The FEM is becoming more widely used to advance dental technologies (DeTolla et al. 2000, Geng et al. 2001). The FEM has been applied to many aspects of dental implantology, including implant and jawbone properties as well as the implant/bone interface (Menicucci et al. 2002, Canay et al. 1996, Meijer et al. 1993, Rieger et al. 1990, O’Mahony et al. 2000, Zarone et al. 2003, Patra et al. 1998). However, no published finite element study is found to investigate the stress profile within the jawbone during the implantation process itself. It is essential for the dentist's to have a thorough understanding of the stress profile within the jawbone to guarantee a successful implantation. In this study, Strand7 (Strand7 Pty Ltd 2004) finite element analysis (FEA) system is adopted to model and analyse the implantation process in a step-wise manner.

Various factors play a role in achieving the ideal implantation process. These include the torque applied to the implant, the insertion speed, the preparation of the site prior to insertion and the clinical health of the patient. A study of 23 patients by Ottoni et al. (2005), found that of 10 implants which failed, 9 had been placed with an insertion torque of $20 \mathrm{Ncm}$. It was concluded that the survival rate was independent of implant length, site position, and bone quality and quantity. It was also concluded that to achieve osseointegration, the insertion torque must exceed $32 \mathrm{Ncm}$. Schmid et al. (2002) found that $80 \%$ of the highest applied torque is used during the final few turns in the implantation process. It was also found that $15-20 \%$ of the highest applied torque is used at the initial stages of implantation. The ultimate aim during implantation is to ensure that the bone in particular cancellous does not exhibit traumatic fracturing. This implies that an ideal stress level within the cancellous bone should be maintained during and after implantation to ensure optimum wound healing. Published literature (Rieger et al. 1990, O'Mahony et al. 2000) indicated that a stress level between 250psi $(1.72 \mathrm{MPa})$ and $400 \mathrm{psi}(2.76 \mathrm{MPa})$ within the surrounding cancellous bone is ideal for bone growth. This stress level is used as a reference to evaluate the results obtained in this study.

The physical health of the patient also influences the success rate of the implant. A strong bone structure and healthy soft tissues are required. If the patient suffers from a systemic disease, the success rate for implants decreases dramatically. Other less obvious factors which might influence the success of the implantation process include the effect of anxiety experienced by the patient caused by the anticipation of pain during implant insertion. Some researchers (Eli et al. 1997, 2003, Brand et al. 1995, Soh \& Yu 1992, Wong \& Lytle 1991) stated that implant insertion is one of the most stressful and anxiety-provoking procedures in dentistry. Although the success or failure of implantation is affected by a number of factors, the present study focuses on the mechanical process of insertion and its effect on the stress profile within the mandible. 


\section{Materials and Methods}

Replicating a realistic implantation process through the use of FEM is the main objective of this paper. This objective is addressed by firstly constructing a three dimensional (3D) model of the implant itself, followed by those for the cortical and cancellous bone. Figures 1 a) and b) show the implant model consisting of 2404 brick elements and 3912 nodes. The implant is cylindrical without taperage and is parallel threaded with $1 \mathrm{~mm}$ pitch thread.

Figures 2 a) and b) show the dimensions for the jawbone section used in this analysis. The dimensions are based on CT scanned images of a posterior section of the mandible. The cortical bone has a set thickness of 1.3mm (O'Mahony et al. 2001), with 1940 brick elements and 4280 nodes. The cancellous bone has 14078 brick elements and 25312 nodes. The total numbers of elements and nodes, for the entire implant and mandible model when the implant is fully inserted, are 18422 and 33504 respectively.

The jawbone and implant are very complex structures in real life. Compared to the existing studies, the present study has increased complexity in its finite element model in that the total numbers of elements and nodes are more than doubled than those used in previous studies, for example, by Lewinstein et al. (1995).

An important criteria for simulating a realistic implantation technique is the loading and boundary conditions, in other words, the applied torque and restraints. Figures $3 \mathrm{a}$ ), b) and c) show the time dependant torque that is positioned at the top of the implant and the fixed constraints in the distal direction. The torque is replicated by applying four concentrated tangential forces, as shown in Figure $3 \mathrm{~b}$ ). Details of the time dependant torque are discussed further in Section 3.

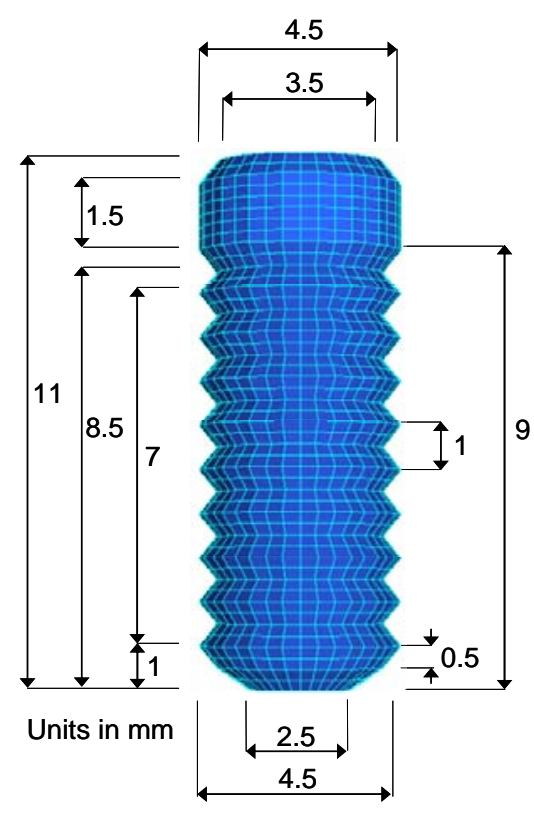

(a) Dimensions

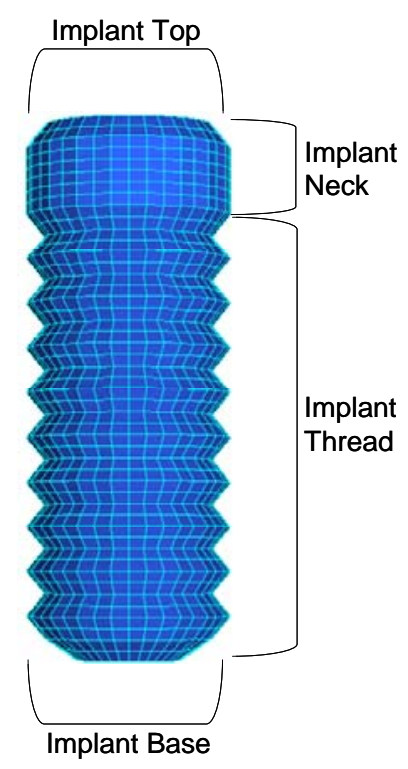

(b) Description of components

Fig. 1. Finite element model of dental implant 


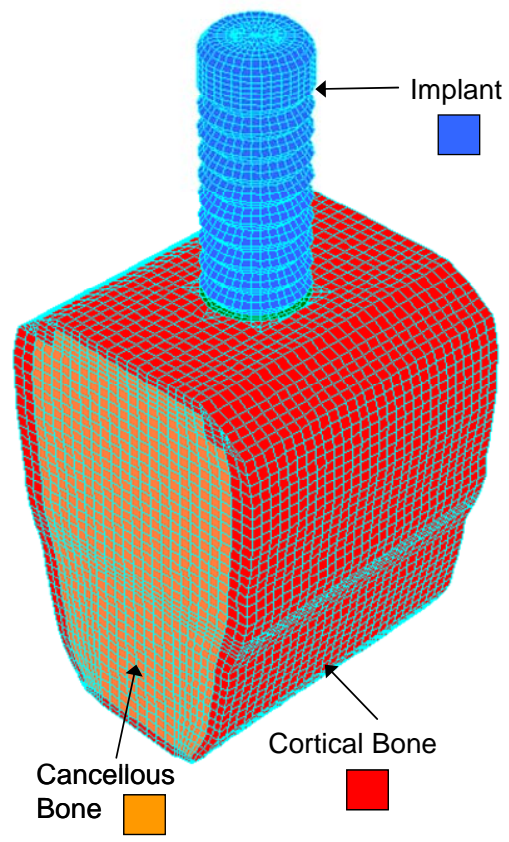

(a) Full model

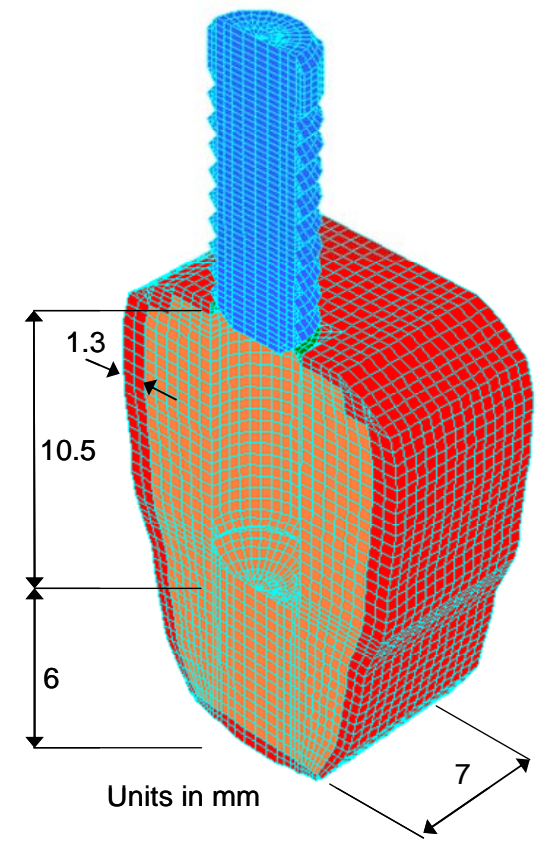

(b) Half model

Fig. 2. Implant and jawbone model prior to implantation.

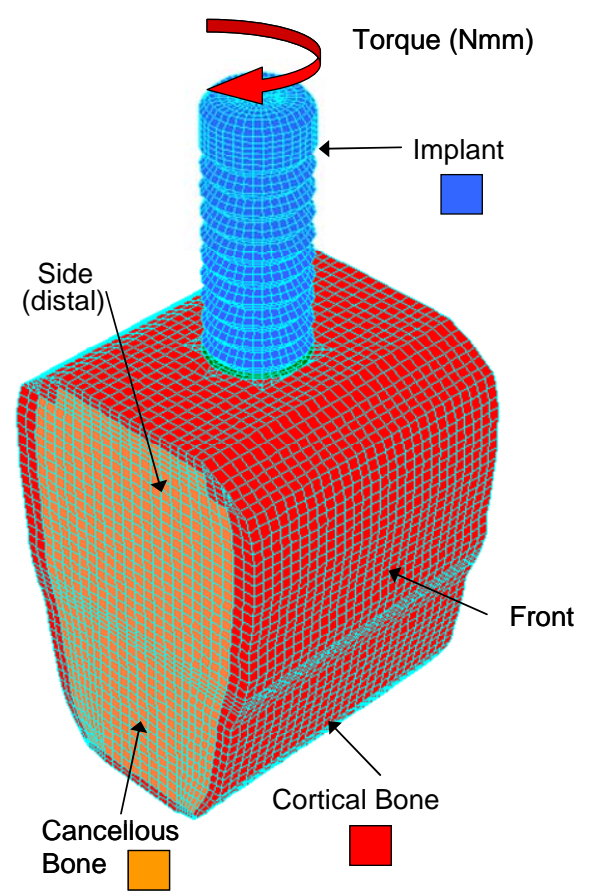

(a) Torque applied to implant model

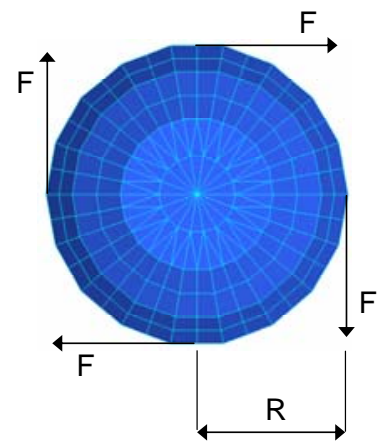

$\mathrm{R}=$ radius of implant $(\mathrm{mm})$

$\mathrm{F}=$ nodal force applied to implant top $(\mathrm{N})$

$\mathrm{T}=$ torque resulting from $\mathrm{F}$ and $\mathrm{R}(\mathrm{Nmm})$

$$
\mathrm{T}=4 \times \mathrm{F} \times \mathrm{R}
$$

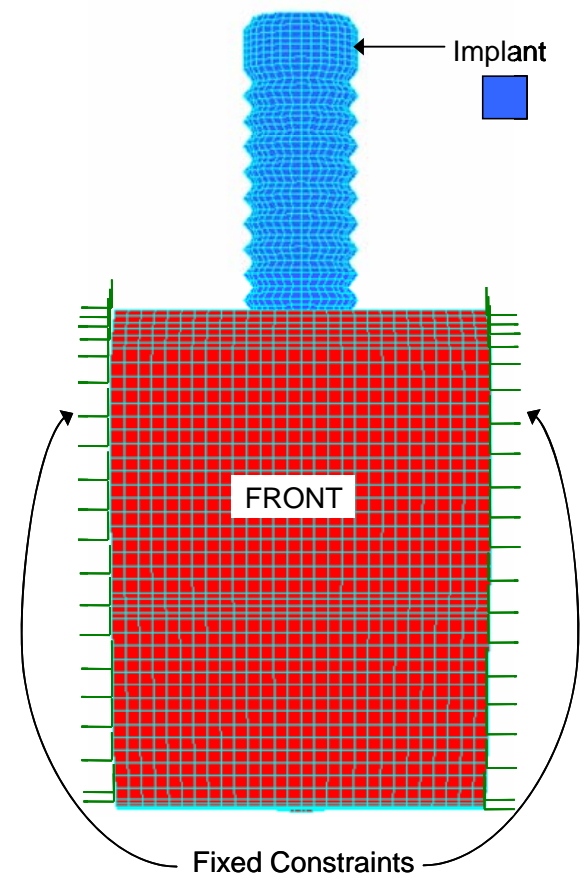

(c) Location of fixed constraints

(b) Equivalent tangential forces applied to implant top

Fig. 3. Load and boundary conditions applied to the implant and jawbone. 
The material properties of implant and jawbone used in this study are shown in Table 1. The implant properties are determined based on the commonly used values for titanium (Young's modulus of $110 \mathrm{GPa}$ and Poisson's ratio of 0.3), as suggested by Papavasiliou et al. (1997), Pierrisnard et al. (2002), Patra et al. (1998), Canay et al. (1996), Meijer et al. (1993), Zarone et al. (2003), Lewinstein et al. (1995) and Menicucci et al. (2002). The Young's modulus of jawbone as documented in previous literature (Table 2) has shown to range from 7.5 MPa to 20 MPa. In this study, the average values of Young's moduli of cortical and cancellous bone are taken (see Table 1).

\section{'[Insert Tables 1 and 2 about here]'}

Unlike previous FEA, non-linear material properties are assumed in this study for the cortical and cancellous bones. It is expected that the cortical and cancellous bone would both exceed their respective maximum yield stress during the implantation process, hence the material properties are defined up to the point of fracture (Figures $4 \mathrm{a}$ ) and b) for cortical and cancellous bone, respectively).

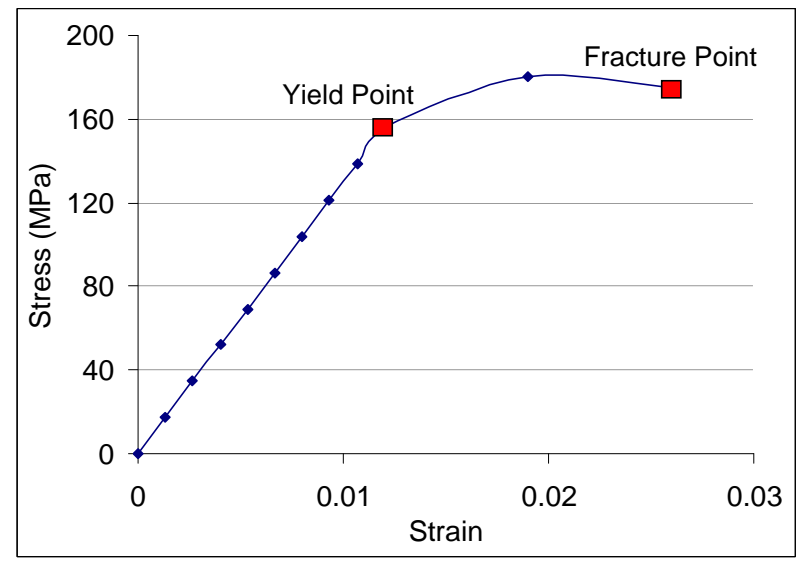

(a) Cortical bone

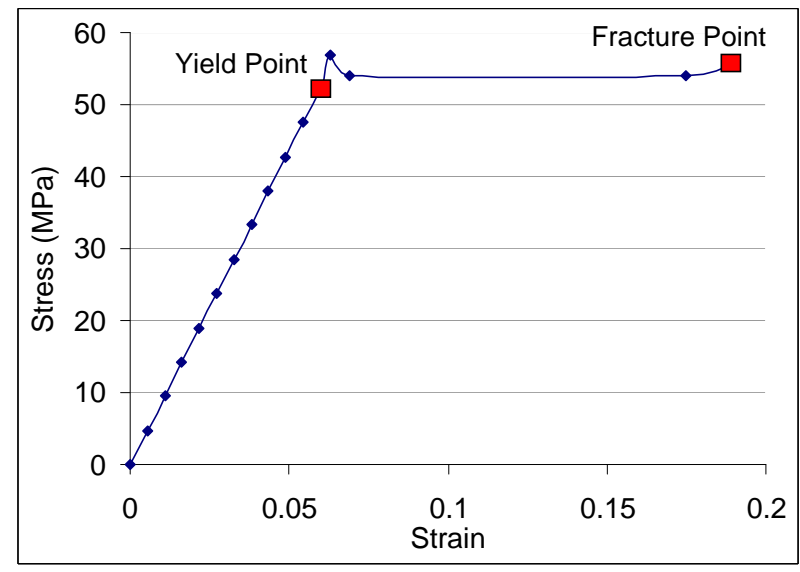

(b) Cancellous bone

Fig. 4. Stress-strain relationship (Burstein et al. 1976).

Theoretically the bone is expected to exceed a specified yield point when the implant is cutting through the bone during insertion. The relationship between the amount of fractured bone and the percentage of osseointegration is still unknown. For the purpose of this study it is assumed that the thickness of the blood and bone fragments is $0.5 \mathrm{~mm}$ filling around the implant threads (Figure 5). The dimensions and location of the interface, which consists of blood and bone fragments, plays an important role in the stress profile within both the cortical and cancellous bone. It is assumed that, at each stage of insertion, the bottom two threads of the implant cut the bone so that the remaining upper threads come in contact with the blood and bone interface. During implant insertion, the stresses along the lines V-V for cancellous bone (Figure 6 a)) and $\mathrm{H}-\mathrm{H}$ for cortical bone (Figure $6 \mathrm{~b}$ )) play a vital role in the success of the implantation. Hence the von Mises stresses along these lines are recorded under increased torque applied to the top of the implant. 


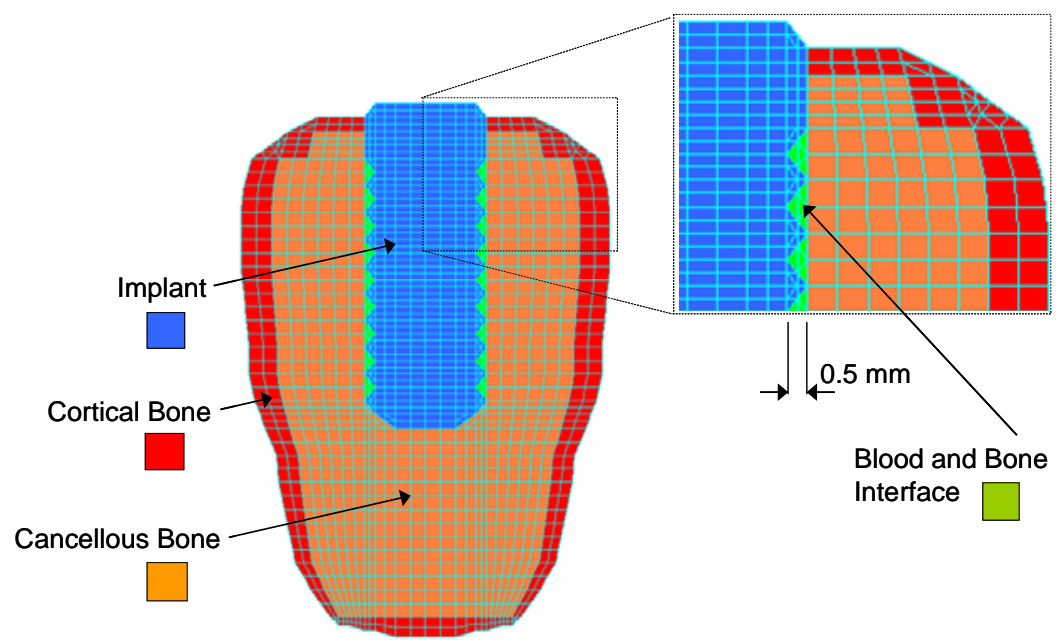

Fig. 5. Location of fragments of blood and bone.

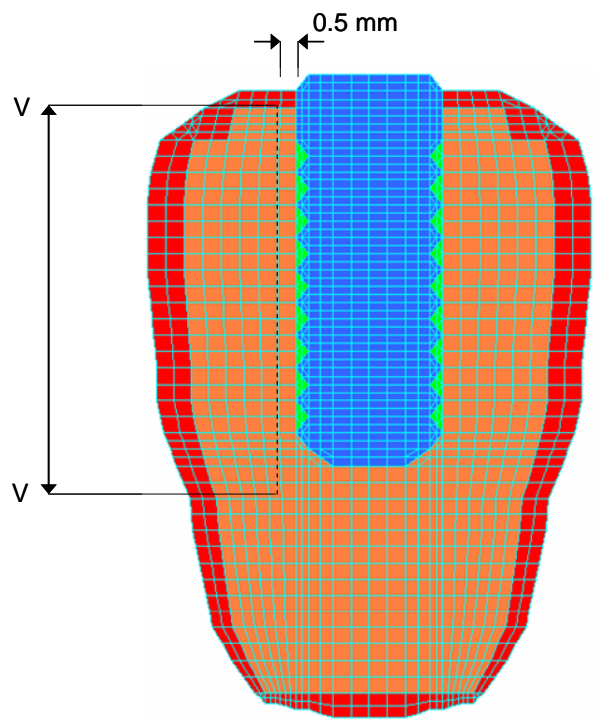

(a) Cancellous bone

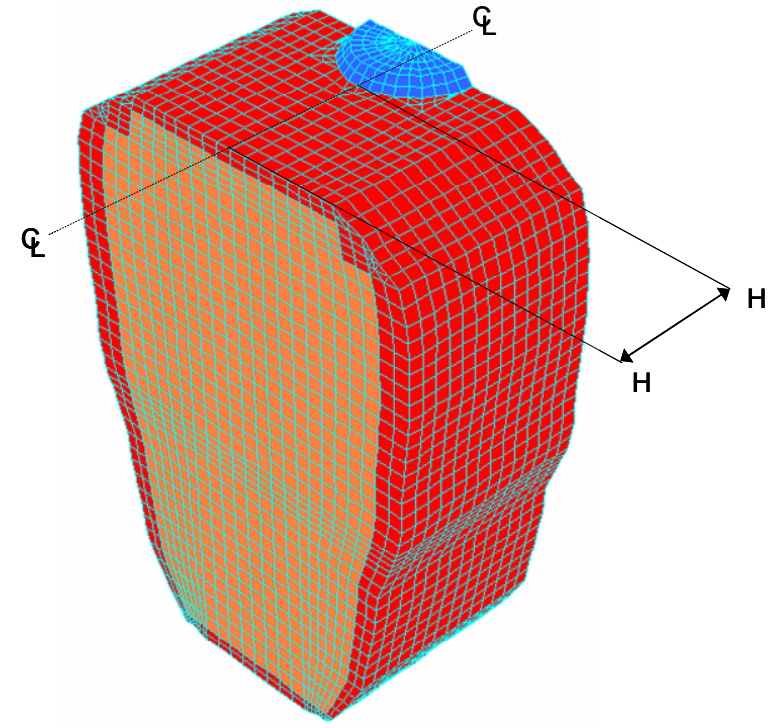

(b) Cortical bone

Fig. 6. Stress profile recording (dashed lines indicate the location).

\section{Simulation Technique}

The expertise of the researchers themselves, along with significant input from both dental and engineering disciplines was utilised in planning the present work. The initial question asked included how to dynamically replicate the process by which the implant is screwed into the jawbone. Ideally the insertion process should be modelled as a continuous one. However, modelling difficulties such as auto re-meshing would have been encountered if a continuous process was to be modelled. Hence a simplified modelling approach is proposed in this study. A series of finite element models are constructed and simulated to replicate the implantation process in a step-wise manner. In other words, an individual model is constructed for each new insertion depth 
of implant. Each model differs from the preceding one by the fact that the implant is inserted $1 \mathrm{~mm}$ deeper into the jawbone. As the implant is $11 \mathrm{~mm}$ long, there are eleven different models to be analysed. When the implantation process is initiated the implant is assumed to be inserted $0.5 \mathrm{~mm}$ into the cortical bone thus replicating the implant tip being pushed slightly into the top surface of bone prior to the application of any torque. As the depth of the implant into the jawbone increases, the area of blood and bone interface also increases which drastically alters the stress profile within the jawbone.

For each of the eleven models, the time periods for each level of the applied torque must be defined (as shown in Figure 7). Setting the correct torque for each time period is difficult because during manual implantation the torque at one specific time is distinct for each implant specialist. The specialist has his/her own opinion and judgement in regard to how much torque to be applied to different bone qualities. The torque over a set period of time as presented in Figure 7 is based on the recommendations given by a number of implant specialists. Due to the fact that a time dependant torque is applied to each one of the eleven models, a nonlinear transient dynamic analysis must be performed. In these analyses, the material nonlinearity is also taken into account according to the stress-strain relationship shown in Figure 4.

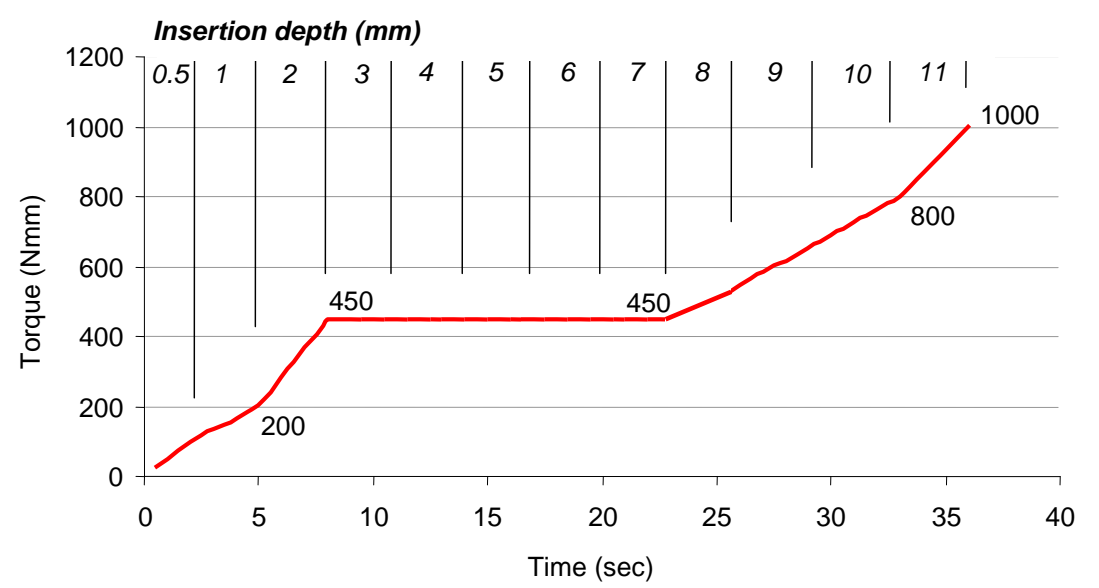

Fig. 7. Torque vs. time during implantation.

Figure 7 indicates that the torque applied to the top of the implant increases rapidly from 0 to $450 \mathrm{Nmm}$ during the first 7 seconds ( $3 \mathrm{~mm}$ implant insertion into the jawbone). The torque then remains constant at 450 $\mathrm{Nmm}$ up to 23 seconds ( $7 \mathrm{~mm}$ implant insertion). During the final 12 seconds of the implantation process the torque increases up to a maximum of $1000 \mathrm{Nmm}$. The characteristics of the torque vs. time graph can be explained from both theoretical and clinical points of view. As the implant is being screwed into the jawbone, the surface area contact between the implant and surrounding bone increases leading to a higher degree of resistance to the implant entering the jawbone, thus a larger level of torque is required to insert the implant at a constant speed. Findings by Schmid et al. (2002) confirm the characteristics of the torque vs. time relationship in that the highest applied torque is used during the final few turns in the implantation process. The assumed torque vs. time relationship is also supported by Ottoni et al. (2005) who stated that in order to achieve osseointegration the level of applied torque must exceed $320 \mathrm{Nmm}$, hence the torque used in this analysis allows for the optimum osseointegration to occur.

\section{Results}

The recorded stress profile within both cortical and cancellous bone during the implantation process is discussed in this section. The stress profiles along the lines V-V and H-H (Figure 6) are plotted for each insertion stage. 


\subsection{Stress profile in cancellous bone}

The von Mises stresses at highlighted nodal points along line V-V (see Figure 6 a)) are recorded for each time step as shown in Figure 8. The implant insertion depth is also indicated in the figure. The stress contour within the cancellous bone for the final stage of each insertion depth is presented on the left of each stress distribution plot. Note that Figure $8 \mathrm{~d}$ ) has two representations of the stress contour, the left is for the time period between 8.5 and 11 seconds and the right is for 20.5 to 23 seconds.

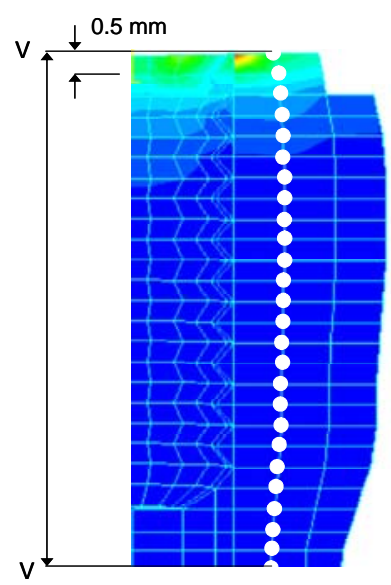

a) $0.5 \mathrm{~mm}$

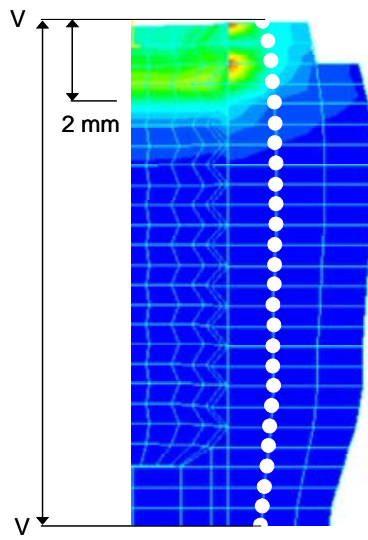

c) $2 \mathrm{~mm}$
Stress (MPa)

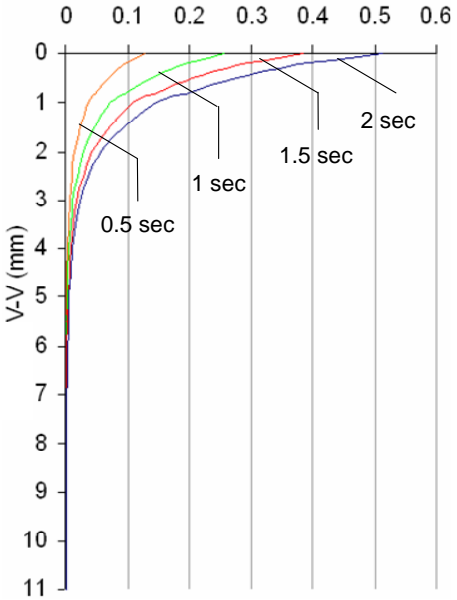

b) $1 \mathrm{~mm}$

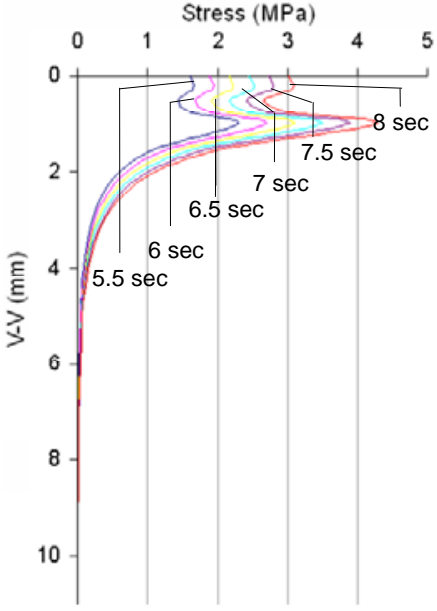

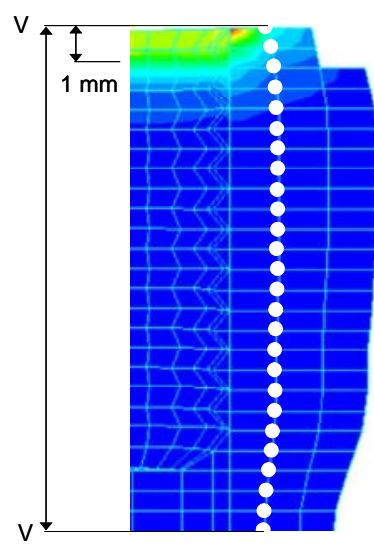
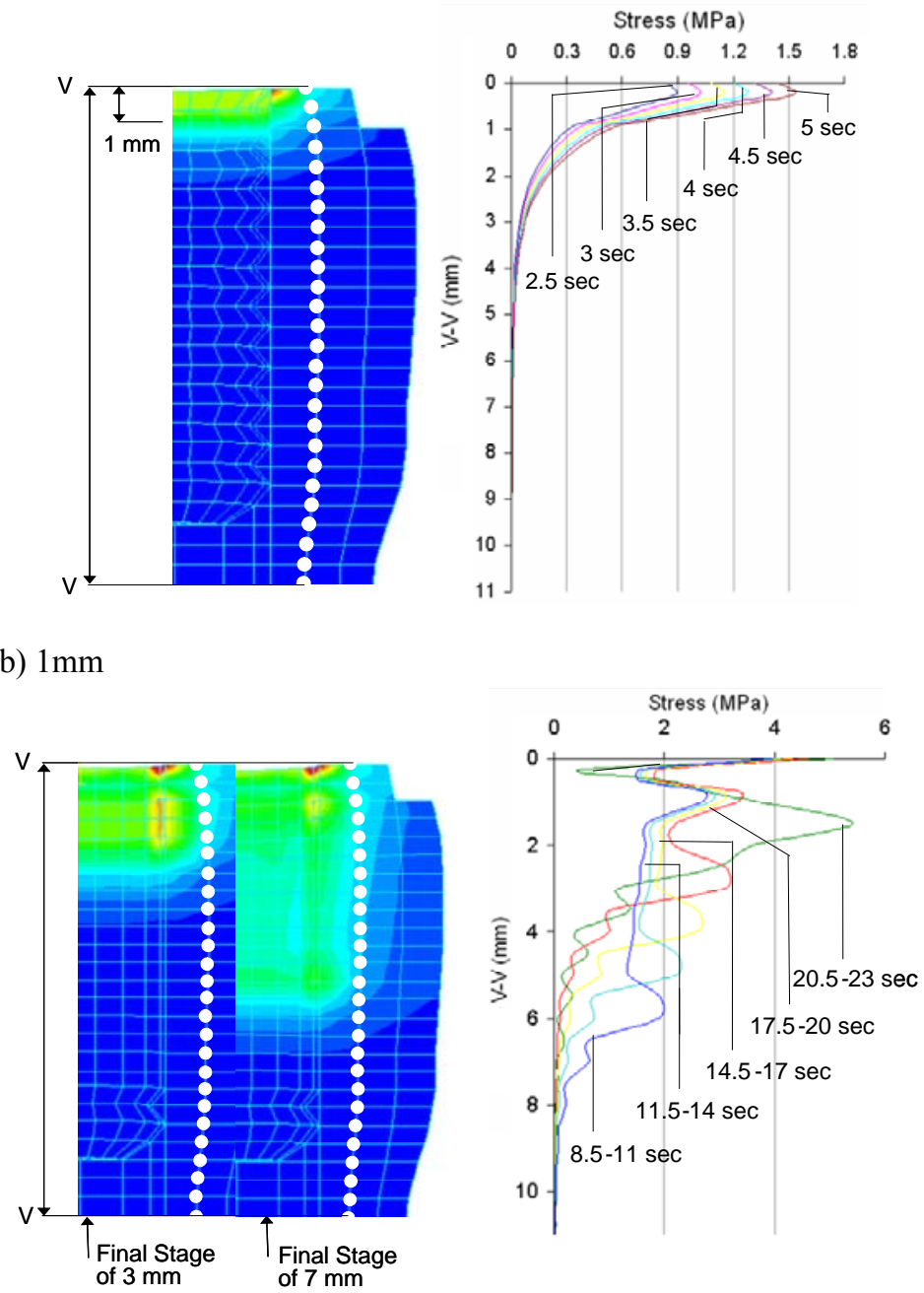

d) $3-7 \mathrm{~mm}$ 


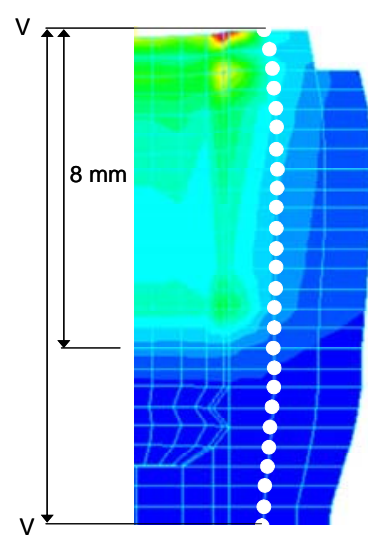

e) $8 \mathrm{~mm}$

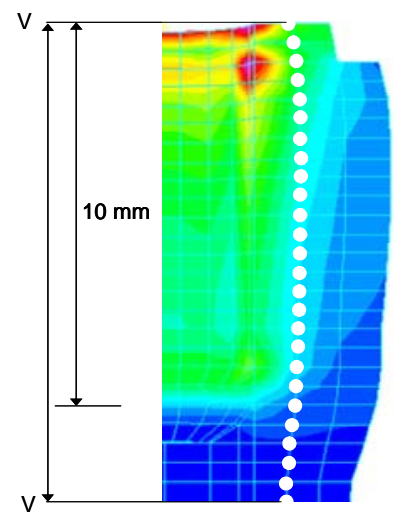

g) $10 \mathrm{~mm}$
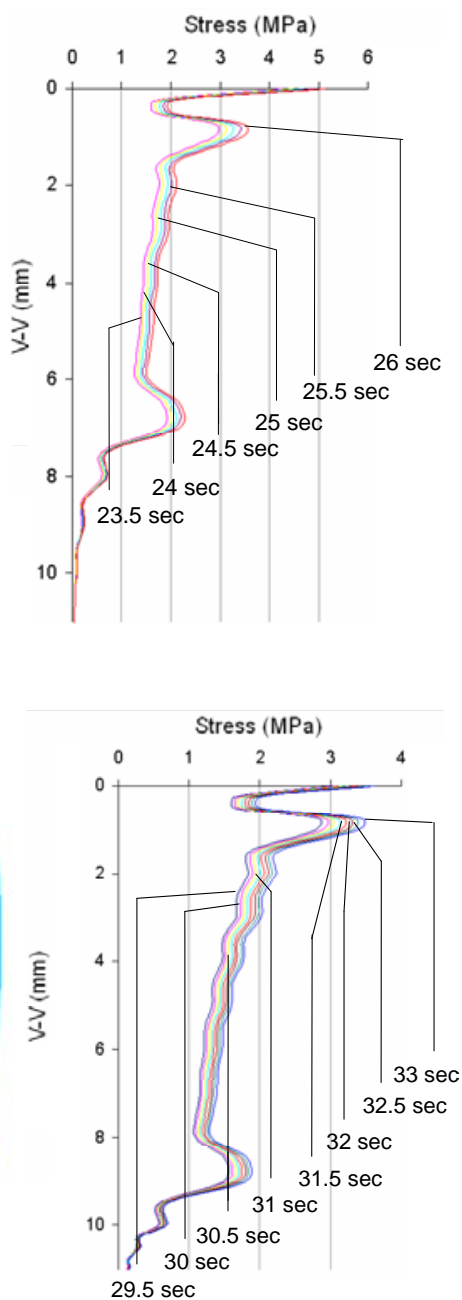

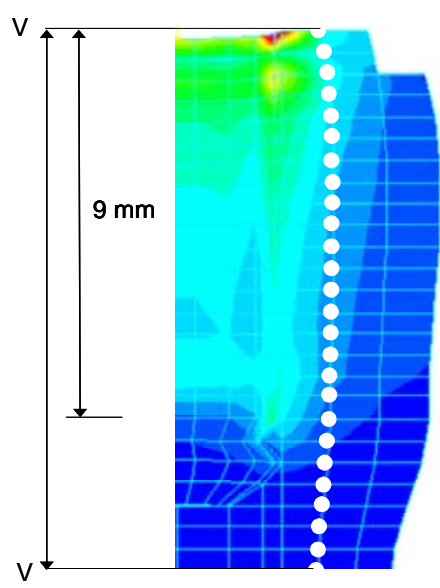

f) $9 \mathrm{~mm}$

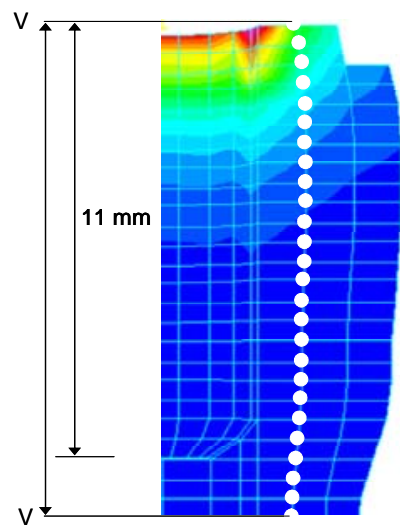

h) $11 \mathrm{~mm}$
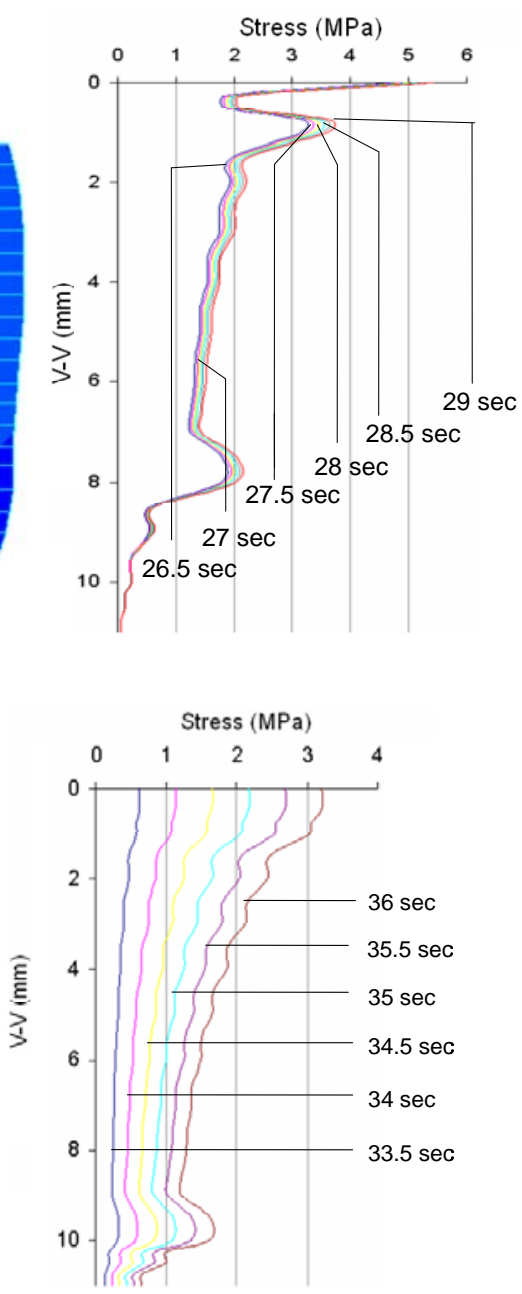

Fig. 8. Stress profile within cancellous bone at each insertion stage (implant being inserted from 0.5 to $11 \mathrm{~mm}$ ).

For all insertion depths, it is evident that when the torque increases the stress level also increases. From the time period 0.5 to 2 seconds, as shown in Figure 8 a), the magnitude of the stress has a maximum variation of $0.4 \mathrm{MPa}$. It can be seen that the stress profile peeks at the top point along the line V-V. The peek in stress is due to the fact that the implant is only inserted $0.5 \mathrm{~mm}$ into the cortical bone. This also causes relatively low stress in cancellous bone as the implant is not in direct contact with the cancellous bone. At this stage the only stress that is experienced by the cancellous bone is transferred through its contact with the cortical bone.

From the time period 2.5 to 5 seconds (Figure $8 \mathrm{~b}$ )) the stress profile experienced an immediate increase in magnitude. The first thread from the base of the implant is in contact with the cancellous bone and the second up, is in contact with the cortical bone. The stress profile indicates a slight peak at $0.5 \mathrm{~mm}$ along the line $\mathrm{V}-\mathrm{V}$, this peak is due to the bottom thread having only a point contact with the cancellous bone thus causing a stress concentration. As the applied torque increases with time an elevation in the stress level is observed.

Figure $8 \mathrm{c}$ ) shows the stress profile from 5.5 to 8 seconds, in general the stress magnitude doubles compared to the preceding step. The implant is inserted $2 \mathrm{~mm}$ into the jawbone and the cancellous bone is in direct contact with the bottom two threads of the implant instead of only the bottom one as in the previous stage. The increase in stress magnitude is also due to the fact that the first layer of interfacial blood and bone 
fragments has formed just after the second to bottom implant thread. The interface is in contact with the cortical bone, where a stress reduction is expected.

The stress distributions for time steps 8.5 to 11 seconds, 11.5 to 14 seconds, 14.5 to 17 seconds, 17.5 to 20 seconds and 20.5 to 23 seconds are shown in Figure $8 \mathrm{~d}$ ). These stages are combined because the applied torque remains constant between 8.5 and 23 seconds. For each set of time steps the implant insertion depth increases by $1 \mathrm{~mm}$ into the jawbone. For all the stress profiles shown in Figure $8 \mathrm{~d}$ ) the stress peaks occur due to the cancellous bone being in direct contact with the implant threads. The stress level along the line $\mathrm{V}-\mathrm{V}$ increases as the applied torque is increased.

The stress profile produced from time 23.5 to 26 seconds (Figure 8 e)) has distinctive stress peaks at the locations corresponding to both bottom and the upper part of the thread. The magnitude of the stress remains relatively in the same range as the previous time period, shown in Figure $8 \mathrm{~d}$ ).

The stress profile recorded form 26.5 to 29 seconds (Figure $8 \mathrm{f}$ )) has many similar characteristics to that of the previous insertion stage. The only major difference is that the stress peak caused by the bottom thread shifts further down towards the base of line V-V. Although the stress profile, from 29.5 to 33 seconds (Figure $8 \mathrm{~g}$ )), also shows a similar characteristic, the stress level slightly reduces. The increase in surface area contact between the cancellous bone and implant is the cause for the reduction in stress level.

Figure $8 \mathrm{~h}$ ) shows the stress distribution at the final insertion stage. There is a larger variation in the stress level at different times. The contact area between the implant and cancellous bone increases but more importantly the cortical bone is in direct contact with the implant hence reducing the stress within the cancellous bone.

Rieger et al.(1990) and O'Mahony et al. (2000) suggested that a stress level between $1.72 \mathrm{MPa}$ and 2.76 MPa within the cancellous bone is ideal for healthy bone growth. The stress levels recorded from 0.5 to 5 seconds is below $1.76 \mathrm{MPa}$, and from 5.5 to 36 seconds a large percentage of the recorded stress levels fall between 1.72 and $2.76 \mathrm{MPa}$. However, various stress peaks occurring at lower and upper thread levels exceed 2.76 $\mathrm{MPa}$. To achieve desirable stress levels leading to optimum osseointegration, the magnitude of the time dependant torque must be properly controlled.

\subsection{Stress profile in cortical bone}

The stress profiles within the cortical bone for all of the eleven insertion stages are shown in Figure 9. The von Mises stresses are recorded at highlighted nodal points along the line H-H (see Figure $6 \mathrm{~b}$ )). The stress contour for each insertion stage is presented below the corresponding stress distribution plot. Note that Figure 9 d) shows the stress profiles between 11 and 20.5 seconds under the constant applied torque. This time period corresponds to the insertion depth 3-7mm. Note also that the stress contour presented in Figure $9 \mathrm{~d}$ ) is for the insertion depth of $7 \mathrm{~mm}$ only. 

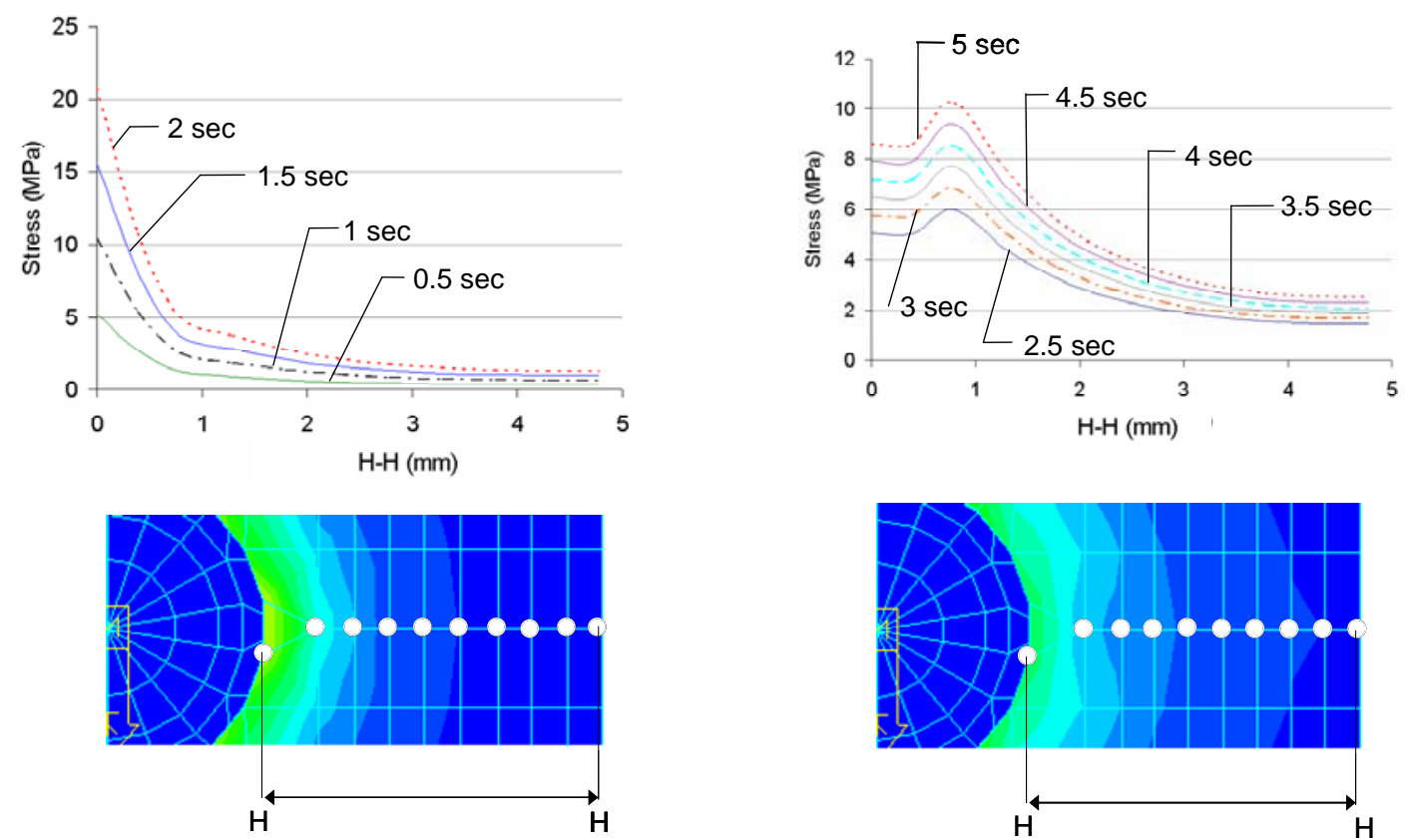

a) $0.5 \mathrm{~mm}$

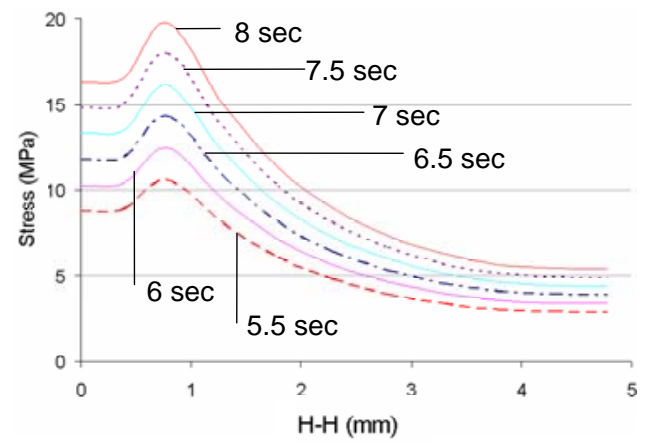

b) $1 \mathrm{~mm}$
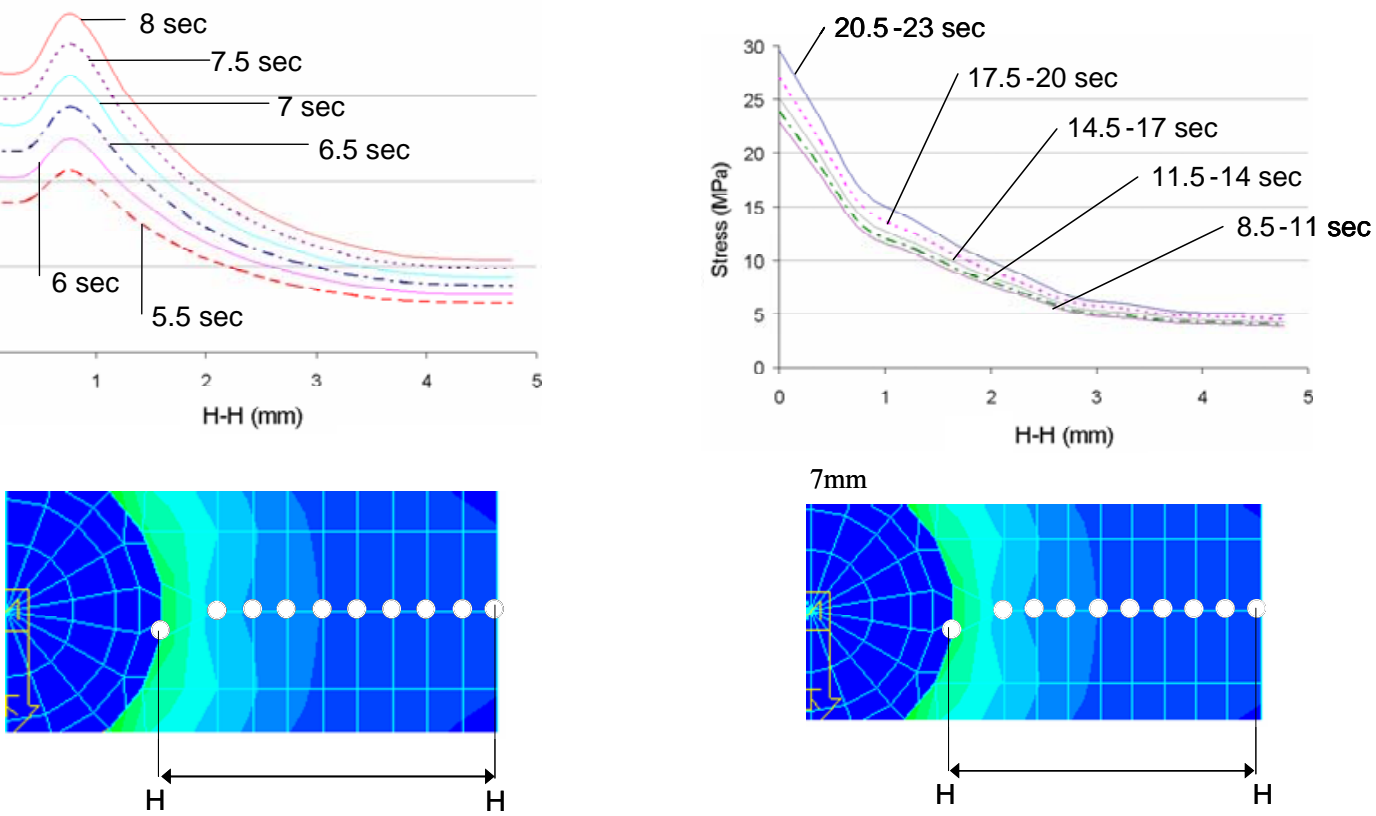

c) $2 \mathrm{~mm}$

d) $3-7 \mathrm{~mm}$ 

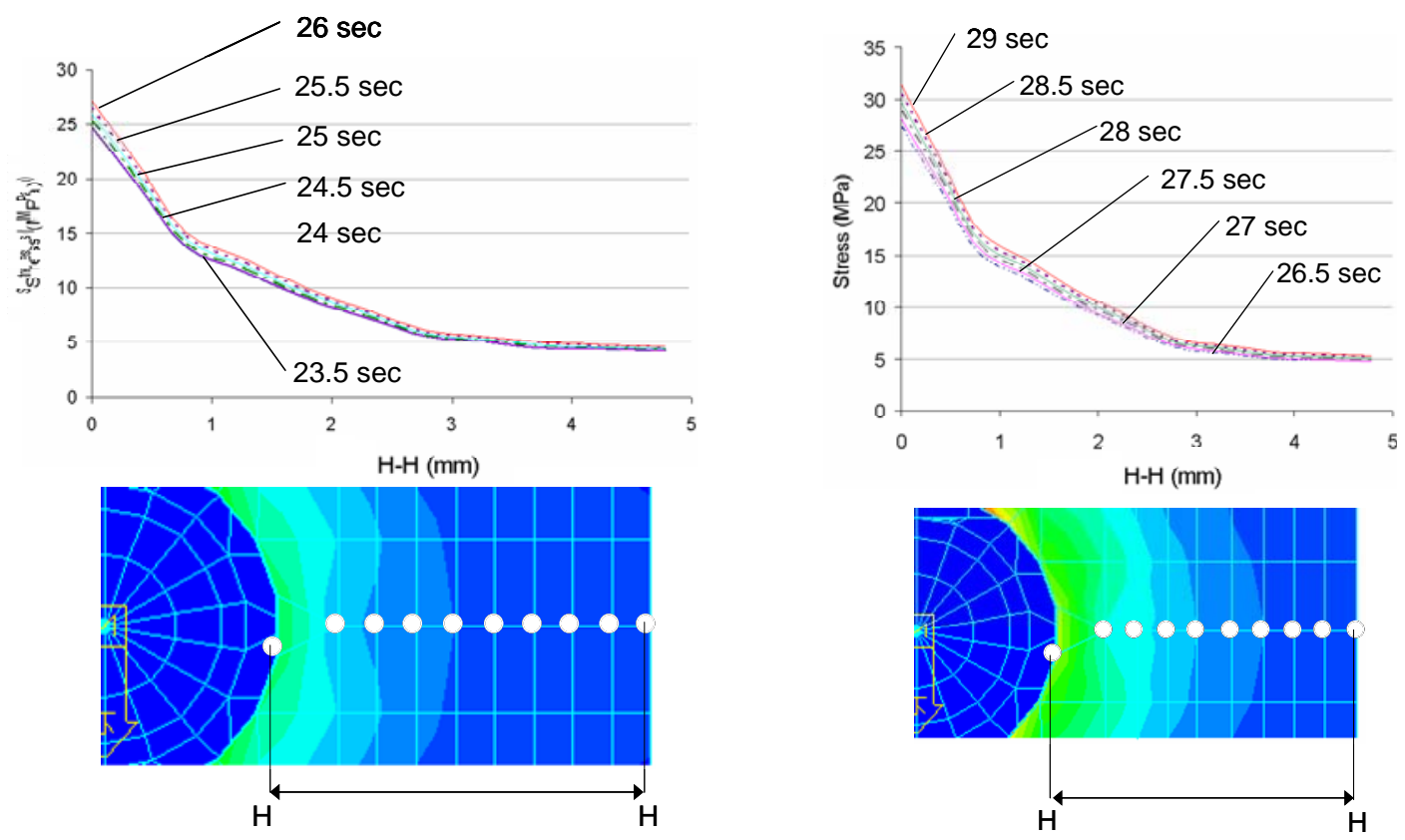

e) $8 \mathrm{~mm}$

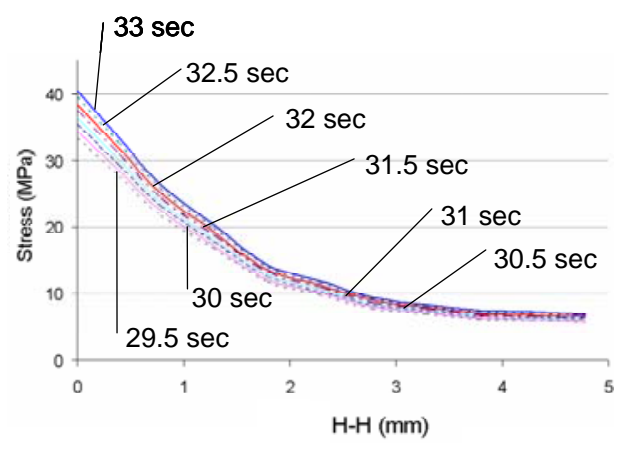

f) $9 \mathrm{~mm}$
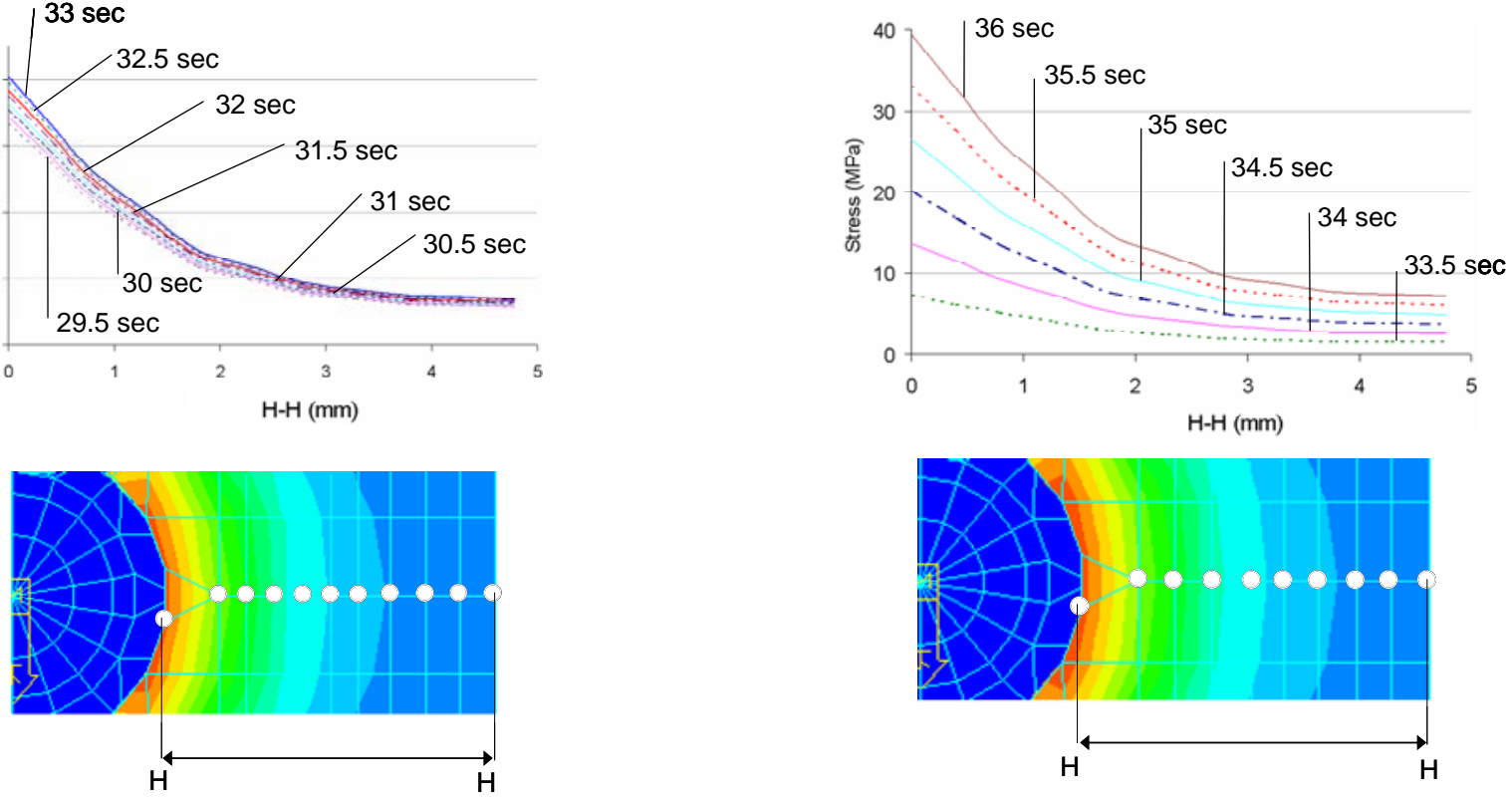

g) $10 \mathrm{~mm}$

h) $11 \mathrm{~mm}$

Fig. 9. Stress profile within cortical bone at each insertion stage (implant being inserted from 0.5 to $11 \mathrm{~mm}$ ).

With reference to Figure 9 a) for the time period between 0.5 and 2 seconds, the maximum stress magnitude occurring adjacent to the implant increases from 5 to $20 \mathrm{MPa}$. However, the stress magnitude decreases significantly to below $2 \mathrm{MPa}$ at increased distance away from the implant neck.

For time period between 2.5 and 5 seconds (Figure $9 \mathrm{~b}$ )), the stress at the neck decreases to a range of 5 to 8 $\mathrm{MPa}$ when compared to stage one. A possible cause is that the force exerted through the implant is shared between the cortical and cancellous bone hence reducing the stress in the vicinity of the implant thread. This in turn causes the stress to peak at $1 \mathrm{~mm}$ distance away from the implant. Note also that, at this stage, no interfacial blood and bone fragments are formed between the bones and the implant. 
From time 5.5 to 8 seconds (Figure $9 \mathrm{c}$ )) the stress profile has similar characteristics to the previous stage. A blood and bone interface formed above the second implant thread, leading to a stress increase at the contact between the implant thread and the cortical bone.

Figure 9 d) shows the stress distribution for time periods between 8.5 and $11,11.5$ and $14,14.5$ and $17,17.5$ and 20, 20.5 and 23 seconds. The characteristics of the stress profile are different from the previous insertion stages. This is due to the fact that the cancellous bone has increased contact with the blood and bone interface. The maximum stress between 23 and $30 \mathrm{MPa}$ is reached at the implant neck, which is nearly doubled when compared to the previous stage.

The stress profiles shown in Figures 9 e), f) and g) are very similar to those shown in Figure 9 d), apart from the fact that the variation in the stress profiles becomes insignificant. It is noted that the maximum stress adjacent to the implant neck increases with time and insertion depth.

At the final two insertion stages (10mm and $11 \mathrm{~mm}$ ) shown in Figures $9 \mathrm{~g}$ ) and h), the implant neck is in direct contact with the cortical bone where no blood and bone interface is present. Hence the stress next to the implant neck reaches the maximum (ie. about $40 \mathrm{MPa}$ ).

\subsection{Stress profiles at specific locations in cancellous and cortical bone}

The recorded stress profiles discussed in the preceding sections are related to the stress magnitude along the line $\mathrm{V}-\mathrm{V}$ or $\mathrm{H}-\mathrm{H}$. However, recording the stress at specific brick elements, $\mathrm{B}_{\mathrm{CAN}}$ and $\mathrm{B}_{\mathrm{COR}}$, for both cancellous and cortical bone respectively is equally important because it can offer a better understanding of the stress experienced by a specific region of bone. The brick elements are located as shown in Figure 10 where $\mathrm{B}_{\text {CAN }}$ corresponds to the top point of line $\mathrm{V}-\mathrm{V}$ and $\mathrm{B}_{\mathrm{COR}}$, the left point of $\mathrm{H}-\mathrm{H}$.

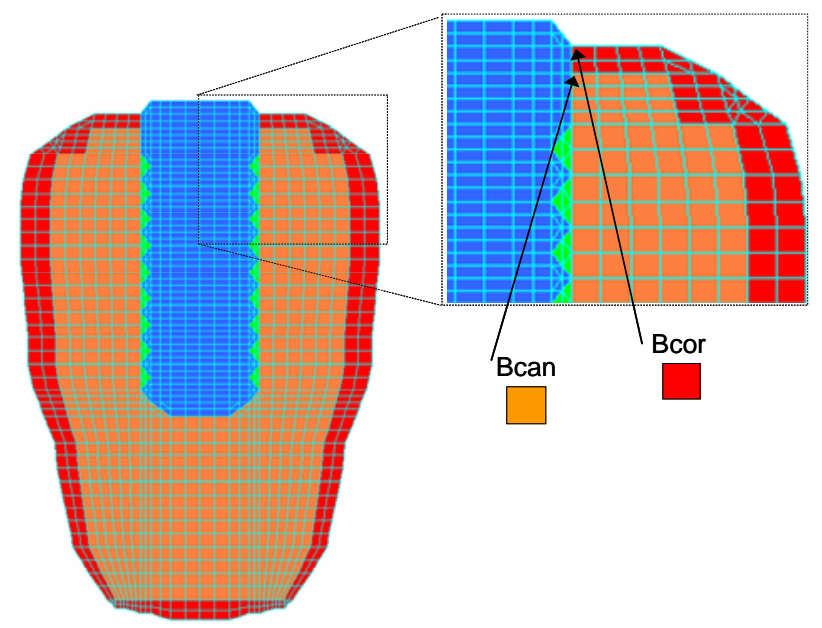

Fig. 10. Location of brick elements $\mathrm{B}_{\mathrm{CAN}}$ and $\mathrm{B}_{\mathrm{COR}}$.

The von Mises stress at location $\mathrm{B}_{\mathrm{CAN}}$ is shown in Figure 11 during the time period between 0 and 36 seconds. Note that the insertion depths are also indicated in the figure. The stress profile during the entire insertion process is described in detail in Table 3. 


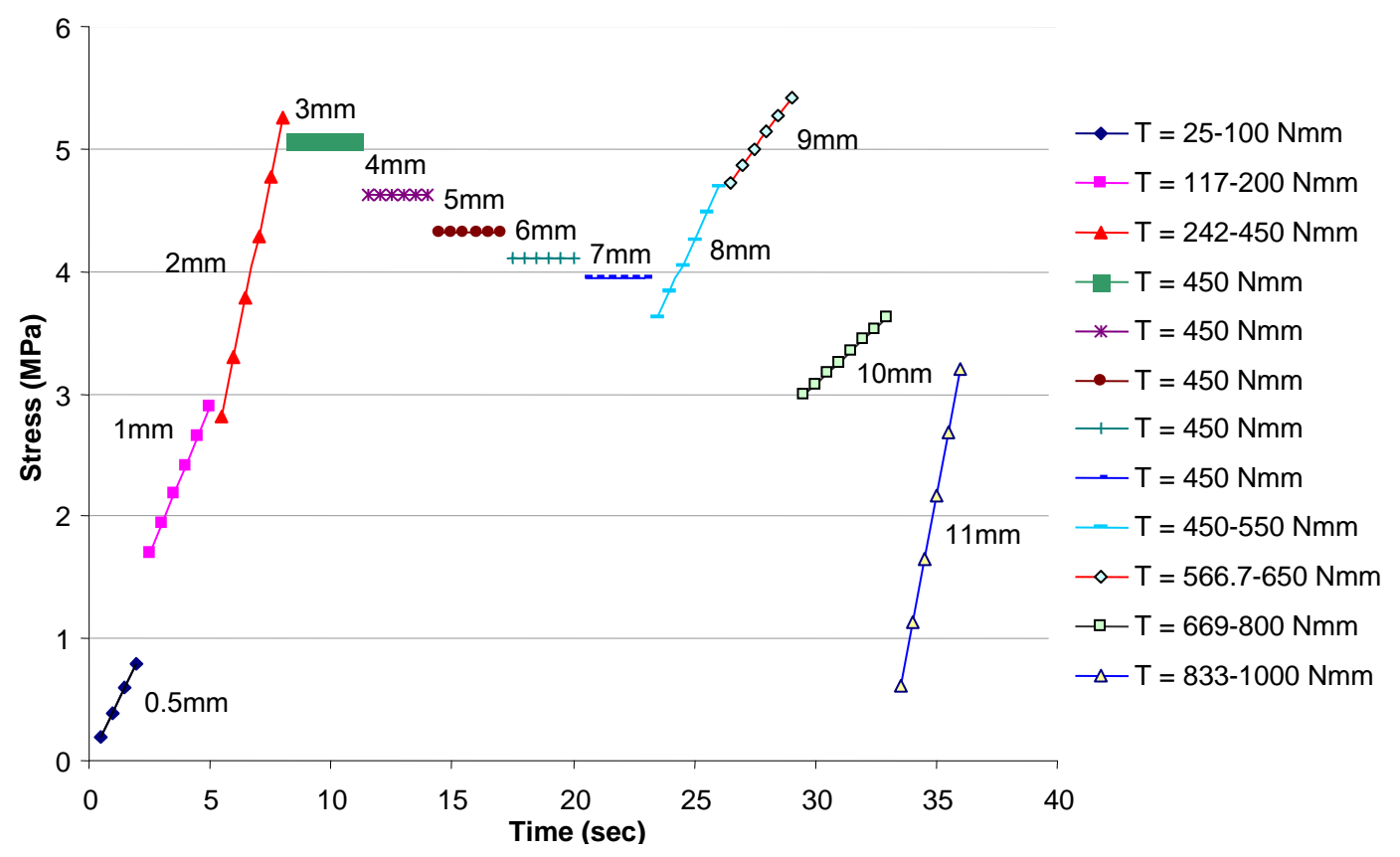

Fig. 11. Stress profile at location $\mathrm{B}_{\mathrm{CAN}}$.

'[Insert Table 3 about here]'

The von Mises stress recorded at $\mathrm{B}_{\mathrm{COR}}$ is presented in Figure 12, from 0 to 36 seconds. Again the insertion depths are indicated for the eleven time periods. The descriptions of the stress profile at $\mathrm{B}_{\mathrm{COR}}$ are detailed in Table 4.

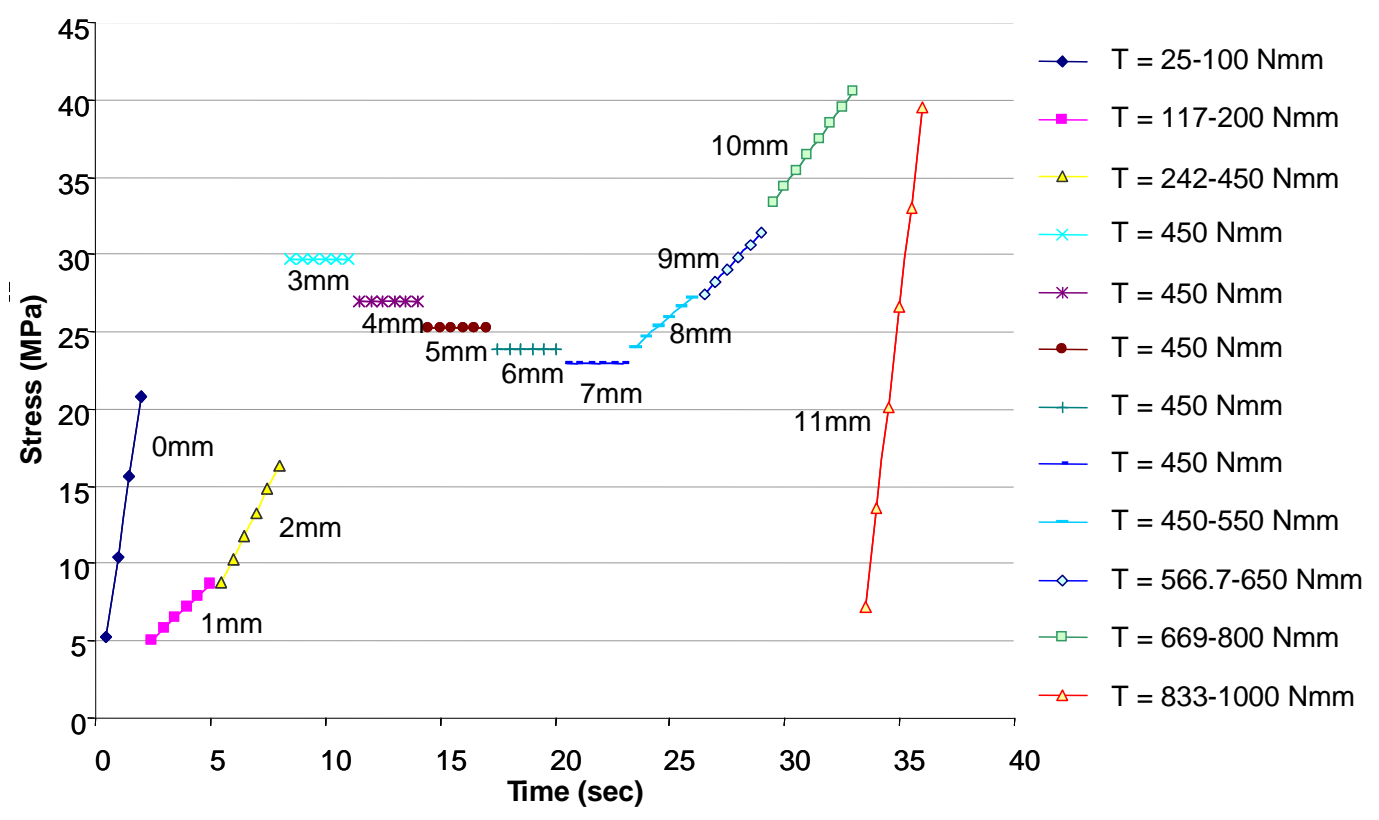

Fig. 12. Stress profile at location $\mathrm{B}_{\mathrm{COR}}$. 


\section{'[Insert Table 4 about here]'}

\section{Discussion}

The finite element method (FEM) has been used extensively to predict the biomechanical performance of various dental implant designs as well as the effect of clinical factors on the success of an implantation. It has been identified that the principal difficulty in simulating the mechanical behaviour of a dental implant is the modelling of the living human bone tissue and its response to applied mechanical forces. Research has been conducted on the length, diameter and shape of implants as well as the biomechanical bond formed between the implant and the jawbone. An in-depth understanding of the stress profiles experienced by the implant and more importantly within the surrounding jawbone can be gained through the use of the FEM.

The analysis undertaken in this paper is to replicate the implantation process in a step-wise manner, with the objective of advancing the current understanding of the stress characteristics within the mandible. The stresses predicted in both the cancellous and cortical bone are discussed in some detail. Stress characteristics for the cancellous bone included elevated stress levels at the top and bottom of the line V-V. Stress transferred through the contact between the cancellous and cortical bone could be a possible explanation for the high stress levels at the top of the cancellous bone. Another factor which might have led to elevated stress levels at the top of the line $\mathrm{V}-\mathrm{V}$ is the fact that a greater moment is exerted at the implant entrance into the cortical bone. The cortical bone experienced a maximum stress adjacent to the implant neck which increased with time and insertion depth. At the base of the implant a high stress level is due to the fact that the implant is in direct contact with the cancellous bone with no blood and bone interface. The stress distributions examined in this study offers some insight into the performance of the cancellous and cortical bone during the implantation process. An important factor to consider in order to improve the insertion technique is the insertion torque and the duration of application. The optimum insertion torque and the set time periods for each level of torque applied are the controlling factors that would help produce ideal stresses within the jawbone throughout the entire implantation process. The outcome of this study will assist the clinician to perform a patient specific implant treatment in a more quality-controlled manner.

\section{Conclusion}

A simplified and efficient 3D modelling procedure is proposed in this study to examine the stress characteristics within the mandible during the implantation process. The study takes into account the realistic geometry, material properties, loading and support conditions for both implant and jawbone as well as the biomechanical implant-jawbone interface. A major modelling and simulation assumption made in this study is that the implantation process is simulated in a step-wised manner instead of a continuous process. This assumption is primarily related to the software capabilities. It should be noted that this research is a pilot study aiming to offer an initial understanding of the complicated stress distribution characteristics due to the increasing time-dependant torque.

Future work includes the variation of the torque applied during the implantation process. The magnitude of applied torque and the duration of its application drastically influence the stress level which in turn affects the outcome of implantation. Based on the initial data obtained in this study, more sophisticated software should be used in order to simulate the full dynamical process of implantation. 


\section{Acknowledgements}

This work is made possible by the collaborative support from Griffith's School of Engineering and School of Dentistry and Oral Health. A special thank goes to Mr John Divitini and Mr Fredrik Engman from Neoss Limited, UK for their endless contribution.

\section{Appendix}

\subsection{Tables}

Table 1. Material properties of finite element models.

\begin{tabular}{lllll}
\hline & Dental Implant & Cortical Bone & Cancellous Bone & Blood Interface \\
\cline { 2 - 5 } Young Modulus, E $(\mathrm{GPa})$ & 102 & 13 & 9.5 & 0.07 \\
Poissons Ratio, $\mathrm{V}$ & 0.3 & 0.35 & 0.3 & 0.3 \\
Density, $\rho\left(\times 10^{-6} \mathrm{~kg} / \mathrm{mm}^{3}\right)$ & 4.54 & 1.5 & 1.5 & 1.5 \\
\hline
\end{tabular}

Table 2. Assumed material properties for different types of bone.

\begin{tabular}{|c|c|c|c|c|c|c|c|c|c|c|c|c|}
\hline Source & & $\begin{array}{l}\text { Papavasiliou } \\
\text { et al. (1997) }\end{array}$ & $\begin{array}{l}\text { Pierrisnard } \\
\text { et al. (2002) }\end{array}$ & $\begin{array}{l}\text { Patra } \\
\text { et al. } \\
(1998)\end{array}$ & $\begin{array}{c}\text { Canay et } \\
\text { al. } \\
(1996)\end{array}$ & $\begin{array}{c}\text { Meijer } \\
\text { et al. } \\
(1993)\end{array}$ & $\begin{array}{l}\text { Borchers } \\
\text { \& Reichart } \\
(1983)\end{array}$ & $\begin{array}{c}\text { Zarone } \\
\text { et al. } \\
(2003)\end{array}$ & $\begin{array}{l}\text { Lewinstein } \\
\text { et al. (1995) }\end{array}$ & $\begin{array}{c}\text { Menicucci } \\
\text { et al. } \\
(2002)\end{array}$ & $\begin{array}{l}\text { i Farah } \\
\text { et al. } \\
(1974)\end{array}$ & $\begin{array}{l}\text { MacGregor } \\
\text { et al. (1980) }\end{array}$ \\
\hline \multirow{2}{*}{$\begin{array}{l}\text { Cortical } \\
\text { Bone }\end{array}$} & $\begin{array}{l}\text { Young } \\
\text { Modulus, } \\
\mathrm{E}(\mathrm{GPa}) \\
\end{array}$ & 13.7 & 14 & 7.5 & 19.73 & 13.7 & 13.7 & 15 & 20 & 13.7 & 10 & $* \mathrm{~N} / \mathrm{A}$ \\
\hline & $\begin{array}{l}\text { Poissons } \\
\text { Ratio, v }\end{array}$ & 0.3 & 0.35 & 2.7 & 0.3 & 0.3 & 0.3 & 0.25 & 0.3 & 0.3 & 0.3 & ${ }^{*} \mathrm{~N} / \mathrm{A}$ \\
\hline \multirow{2}{*}{$\begin{array}{l}\text { Cancell } \\
\text { ous } \\
\text { Bone }\end{array}$} & $\begin{array}{l}\text { Young } \\
\text { Modulus, } \\
\mathrm{E}(\mathrm{GPa}) \\
\end{array}$ & 7.93 & 2.5 & 0.5 & $* \mathrm{~N} / \mathrm{A}$ & 1.37 & $* \mathrm{~N} / \mathrm{A}$ & 1.5 & $* \mathrm{~N} / \mathrm{A}$ & 1.37 & $* \mathrm{~N} / \mathrm{A}$ & 0.25 \\
\hline & $\begin{array}{l}\text { Poissons } \\
\text { Ratio, v }\end{array}$ & 0.3 & 0.3 & 0.3 & $* \mathrm{~N} / \mathrm{A}$ & 0.3 & $* \mathrm{~N} / \mathrm{A}$ & 0.29 & $* \mathrm{~N} / \mathrm{A}$ & 0.3 & $* \mathrm{~N} / \mathrm{A}$ & 0.3 \\
\hline
\end{tabular}

$[1] * \mathrm{~N} / \mathrm{A}$ - information not available.

Table 3. Explanation of stress profile at $\mathrm{B}_{\mathrm{CAN}}$.

\begin{tabular}{ll}
$\begin{array}{c}\text { Insertion } \\
\text { depth } \\
(\mathrm{mm}):\end{array}$ & Description of characteristics: \\
\hline 0.5 & $\begin{array}{l}\text { The stress magnitude is relatively low because there is no direct contact between the implant and cancellous bone. } \\
\text { The stress increases as the applied torque increases. }\end{array}$ \\
\hline 1 & The bottom thread comes into direct contact with the cancellous bone leading to a sudden increase in the stress. \\
\hline 2 & $\begin{array}{l}\text { The stress increases remarkably and more rapidly at this stage because the cancellous bone is in contact with the } \\
\text { bottom two threads without the blood and bone interface. However the cortical bone comes into contact with the } \\
\text { interface hence increasing the stress within the cancellous bone. }\end{array}$ \\
\hline $3-7$ & $\begin{array}{l}\text { The torque is constant which leads to no change in the stress level for each insertion depth. More surface area contact } \\
\text { between the implant and cancellous bone leads to a gradual decrease in the stress level for each stage of insertion. }\end{array}$ \\
\hline 10 & $\begin{array}{l}\text { The combination of an increased torque and surface area contact between the implant and cancellous bone are } \\
\text { responsible for the increase in stress levels. }\end{array}$ \\
\hline 11 & $\begin{array}{l}\text { Initially at } 669 \text { Nmm torque a decrease in stress occurs due to the fact that the cortical bone comes into contact with } \\
\text { the implant neck thus increasing the stress in the cortical bone whereas reducing that in the cancellous bone. }\end{array}$ \\
& $\begin{array}{l}\text { Finally a further decrease in stress is observed at this stage because the cortical bone absorbs a higher stress. A } \\
\text { decrease in stress from 9mm to } 11 \text { mm of insertion is due to the fact that more implant surface area is in direct contact } \\
\text { with cancellous bone. }\end{array}$ \\
\hline
\end{tabular}

Table 4. Explanation of stress profile at $\mathrm{B}_{\mathrm{COR}}$. 


\begin{tabular}{ll}
\hline $\begin{array}{l}\text { Depth } \\
(\mathrm{mm}):\end{array}$ & $\begin{array}{l}\text { Tescription of characteristics: } \\
\text { evident during this stage. }\end{array}$ \\
\hline 0.5 & $\begin{array}{l}\text { Stress shows a reduction due to the fact that some stresses are transferred to the cancellous bone. A gradual increase in } \\
\text { stress is due to the increase in implant surface area which is in contact with the cortical bone. }\end{array}$ \\
\hline $\mathbf{2}$ & $\begin{array}{l}\text { The cortical bone is in contact with the interfacial blood and bone, however there is a stress concentration at the tip of } \\
\text { the implant thread. Again the stress increases quite rapidly. }\end{array}$ \\
\hline $3-7$ & $\begin{array}{l}\text { The results are similar to those recorded in the cancellous bone. The torque remains constant between } 3 \text { and } 7 m m \\
\text { insertion which leads to no change in the stress levels for each insertion depth. More surface area contact between the } \\
\text { implant and cancellous/cortical bone leads to a step-wise decrease in stress within the cortical bone. }\end{array}$ \\
\hline $8-9$ & The increased torque is responsible for the increase in stress levels. \\
\hline 10 & The increase in stress is due to the implant neck being in direct contact with the cortical bone. \\
\hline & $\begin{array}{l}\text { At } 833 \text { Nmm torque, the cancellous and cortical bone shares the stress, thus a decrease in stress can be seen for both } \\
\text { bones. The stress values increase dramatically during this final stage of insertion due to the cortical bone being the } \\
\text { strongest and thus carrying the majority of the moment exerted through the implant. }\end{array}$ \\
\hline
\end{tabular}

\section{References}

Borchers, L. \& Reichart, P. (1983) Three-dimensional stress distribution around a dental implant at different stages of interface development. Journal of Dentistry Research 62(2): 155 - 159.

Brand, H. S., Gortzak, R. A., Palmer-Bouva, C. C., Abraham, R. E. \& Abraham-Inpijn, L. (1995) Cardiovascular and neuroendocrine responses during acute stress induced by different types of dental treatment. International Dental Journal 45(1): 45 - 48.

Burstein, A. H., Reilly, D. T., Martens, M. (1976) Aging of bone tissue: mechanical properties. The Journal of Bone and Joint Surgery. American volume 58(1): 82 - 86.

Canay, S., Hersek, N., Akpinar, I. \& Asik, Z. (1996) Comparison of stress distribution around vertical and angled implants with finite-element analysis. Quintessence International 27(9): 591 - 598.

DeTolla, D. H., Andreana, S., Patra, A., Buhite, R. \& Comella, B. (2000) Role of the finite element model in dental implants. Journal of Oral Implantology 26(2): 77 - 81.

Eli, I., Bar-Tal, Y., Fuss, Z. \& Silberg, A. (1997) Effect of intended treatment on anxiety and on reaction to electric pulp stimulation in dental patients. Journal of Endodontics 23: 694 - 697.

Eli, I., Schwartz-Arad, D., Baht, R. \& Ben-Tuvim, H. (2003) Effect of anxiety on the experience of pain in implant insertion. Clinical Oral Implants Research 14(1): 115 - 118.

Farah, J. W., Hood, J. A. \& Craig, R. G. (1974) Stresses and deflections in the floor of model cavity preparations. Journal of Oral Rehabilitation 1(2): 207 - 215.

Geng, J. P., Tan, K. B. \& Liu, G. R. (2001) Application of finite element analysis in implant dentistry: a review of the literature. Journal of Prosthetic Dentistry 85(6): 585 - 598.

Lewinstein, I., Banks-Sills, L. \& Eliasi, R. (1995) A finite element analysis of a new system (IL) for supporting an implant-retained cantilever prosthesis. International Journal of Oral Maxillofacial Implants 10(3): $355-366$.

MacGregor, A. R., Miller, T. P. \& Farah, J. W. (1980) Stress analysis of mandibular partial dentures with bounded and free-end saddles. Journal of Dentistry 8(1): 27 - 34.

Meijer, H. J., Starmans, F. J., Steen, W. H. \& Bosman, F. (1993) A three-dimensional, finite-element analysis of bone around dental implants in an edentulous human mandible. Archives of Oral Biology 38(6): 491 496.

Menicucci, G., Mossolov, A., Mozzati, M., Lorenzetti, M. \& Preti, G. (2002) Tooth-implant connection: some biomechanical aspects based on finite element analyses. Clinical Oral Implants Research 13(3): 334 341. 
Meredith, N., Shagaldi, F., Alleyne, D., Sennerby, L. \& Cawley, P. (1997) The application of resonance frequency measurements to study the stability of titanium implants during healing in the rabbit tibia. Clinical Oral Implants Research 8(3): 234 - 243.

O'Mahony, A., Bowles, Q., Woolsey, G., Robinson, S. J. \& Spencer, P. (2000) Stress distribution in the single-unit osseointegrated dental implant: finite element analyses of axial and off-axial loading. Implant Dentistry 9(3): 207 - 218.

O'Mahony, A. M., Williams, J. L. \& Spencer, P. (2001) Anisotropic elasticity of cortical and cancellous bone in the posterior mandible increases peri-implant stress and strain under oblique loading. Clinical Oral Implants Research 12(6): 648 - 657.

Ottoni, J. M., Oliveira, Z. F., Mansini, R. \& Cabral, A. M. (2005) Correlation between placement torque and survival of single-tooth implants. International Journal of Oral Maxillofacial Implants 20(5): 769 - 776.

Papavasiliou, G., Kamposiora, P., Bayne, S. C. \& Felton, D. A. (1997) 3D-FEA of osseointegration percentages and patterns on implant-bone interfacial stresses. Journal of Dentistry 25(6): 485 - 491.

Patra, A. K., DePaolo, J. M., D'Souza, K. S., DeTolla, D. \& Meenaghan, M. A. (1998) Guidelines for analysis and redesign of dental implants. Implant Dentistry 7(4): 355 - 368.

Pierrisnard, L., Hure, G., Barquins, M. \& Chappard, D. (2002) Two dental implants designed for immediate loading: a finite element analysis. International Journal of Oral Maxillofacial Implants 17(3): 353 - 362.

Rieger, R., Mayberry, M. \& Brose, M. O. (1990) Finite element analysis of six endosseous implants. Journal of Prosthetic Dentistry 63(6): 671 - 676.

Schmid, M. R., Schiel, H. J. \& Lambrecht, J. T. (2002) Torque of endosseous dental screw type implants. Schweiz Monatsschr Zahnmed 112(8): 804 - 813.

Strand7 Pty Ltd (2004) Strand7 Theoretical Manual, Sydney, Australia.

Soh, G. \& Yu, P. (1992) Phases of dental fear for four treatment procedures among military personnel. Milatary Medicine 157(6): 294 - 297.

Wong, M. \& Lytle, W. R. (1991) A comparison of anxiety levels associated with root canal therapy and oral surgery treatment. Journal of Endodontics 17(9): 461 - 465.

Zarone, F., Apicella, A., Nicolais, L., Aversa, R. \& Sorrentino, R. (2003) Mandibular flexure and stress buildup in mandibular full-arch fixed prostheses supported by osseointegrated implants. Clinical Oral Implants Research 14(1): 103 - 114. 